\title{
Changing Trends in Caesarean Section: Rate \& Indications
}

\author{
Dr. Swapan Das ${ }^{1}$, Dr. Debasish Char ${ }^{1}$, Dr. Sanjay Sarkar ${ }^{2}$, \\ Dr. Tushar Kanti Saha ${ }^{3}$ \\ ${ }^{I}(R M O$, Dept. of Gynaecology \& Obstetrics, Bankura Sammilani Medical College \& Hospital, Bankura); \\ ${ }^{2}(R M O$, Dept. of Medicine, Bankura Sammilani Medical College \& Hospital, Bankura) \\ ${ }_{3}^{3}$ Asst. Prof., Dept. of Community Medicine, NRS Medical College, Kolkata)
}

\begin{abstract}
:
Objective: The objective of this study is to compare the changes in rate and indication of Caesarean section during 2005 and 2012 after a gap of 7 years. Study Design: Comparative Study. Material and Methods: In this comparative study, 2 years data i.e. of 2005 and 2012 was collected from Hospital record. 2 years data were compared fort Caesarean section rate and trends of indication of Caesarean section. Results: The results showed that in year 2005 the rate of Caesarean section was $13.94 \%$ and in year 2012 it increased to $25.68 \%$. In both years the main indication of Caesarean section was previous Caesarean section followed by dystocia and foetal distress. Conclusion: It is suggested to have obstetric audit by inter departmental meetings to assess the intrinsic role of Caesarean section in influencing the standard management guidelines.
\end{abstract}

Keywords: Caesarean section, Changing trends, Indication, Audit

\section{Introduction}

Caesarean section is one of the most commonly perform surgical procedure in modern obstetrics. The improvements in anaesthesia services, availability of improvised surgical technique and prophylactic use of antibiotic have made Caesarean section a relatively safer procedure in the practice of modern obstetrics. The decision whether to perform a Caesarean section or not is based on the individualised judgement of obstetrician of the hospital where Caesarean section would be performed.

There is no consensus regarding the ideal caesarean section rate; however WHO states that no additional health benefits are associated with a Caesarean section rate above 10 to $15 \%$ (1). The increase in Caesarean section rate has been a global phenomenon. Caesarean section rate in USA is $29.1 \%$ (2), England $21.5 \%$ (3) and in Latin American Countries 40\% (4).

The reason for increase in Caesarean birth are multifactorial and include the increasing number of woman with prior Caesarean delivery, the increase in multifetal gestation, increasing use of intrapartum foetal monitoring, medico legal concerns, maternal autonomy in decision making regarding mode of delivery. Today the previous Caesarean section is the main contributory factor for the high frequency of caesarean delivery worldwide.

Audit plays an important role in the analysis of changing trends in Caesarean delivery rate, the needs and benefits of such changes and to modify the obstetrician's view towards performing Caesarean delivery. This study was conducted because of rising trend in Caesarean section in developing world, as it is worrying because of its adverse consequences in future pregnancies.

\section{Materials \& Methods}

This study was conducted at Department of Obstetrics and Gynaecology B.S. Medical College \& Hospital, Bankura, W.B, Our Department of Obstetrics \& gynaecology maintains a very precise record of all deliveries. The record of all patients who delivered in 2005 and 2012 respectively were collected. All the patients who underwent emergency and elective Caesarean section were included in this study. In this study dystocia includes both non-progress of labour and obstructed labour due to foetal or maternal process.

The percentage of Caesarean section with specific indication was computed for the year 2005 \& 2012 respectively and Caesarean section rate was calculated for both years.

\section{Results}

The result of the study reveals that in the year 2005, total deliveries performed were 15719; out of which 2192 patients underwent Caesarean section thus giving a rate of $13.94 \%$ compared to 20,411 deliveries in the year 2012 with 5243 Caesarean section at a rate of $25.68 \%$

Statistical analysis shows -

- There was drastic increase in the rate of Caesarean deliveries of upto $11.74 \%$ in the year 2012 as compared to year 2005. 
- In the year 2005 main indication for Caesarean section were previous Caesarean section, dystocia, foetal distress and PIH/ eclampsia.

- In the year 2012 the main indication for Caesarean section were previous Caesarean section 1832 (34.94\%) dystocia 748 (14.26\%), foetal distress 716 (13.65\%), PIH /eclampsia 600 (11.44\%), CPD $276(5.26 \%)$ precious pregnancy / BOH 210 (4\%) and breech 204 (3.89\%).

- The main indication for both years study was previous Caesarean section followed by dystocia and foetal distress.

- The percentage of CS performed for previous Caesarean section has shown 34.94\% (1832) in 2012 compared to $28.19 \%$ (618) in 2005. This rise in Caesarean section rate could be because of not taking risk by obstetrician patient.

\section{Discussion}

There has been a steady increase in the rate of Caesarean section in both developed and developing countries. The increasing rate of Caesarean delivery has become an international public health concern. The Caesarean section rate in our study has increased from $13.94 \%$ in 2005 to $25.68 \%$ in 2012. Similar rise in Caesarean delivery rate was seen throughout the world. In USA rate rose from $21 \%$ in 1984 to $24.4 \%$ in 2001 $(5,6)$. In UK it rose from 9\% in 1980 to $21.3 \%$ in 2000 (7, 8). Similar facts reported by Murry S.F. and Serani Pradenas F. regarding Caesarean delivery in Chile, the rate increased from 27.7\% in 1986 to $37.2 \%$ in 1994(9).

In our study, the Caesarean section rate due to previous one or more than one Caesarean section was 28.19\% (618) in 2005 and $34.94 \%$ (1832) in 2012. Our findings are consistent with finding of study at Hyderabad, Pakistan and from Peshwar where the reported incident of repeat Caesarean section is $19.2 \%$; $29.87 \%(10,11)$ respectively. The B.S. medical College Bankura is a Tertiary care hospital which deals with large number of referred and complicated cases. This is one of the important reason for increase no. of repeat Caesarean section in our department.

In our study, dystocia although its contribution to overall Caesarean section rate has fallen from $24.36 \%$ in 2005 to $14.26 \%$ in 2012. This findings consistent with 1962 and 1992 statistics in a teaching hospital in Glasgow U.K., showing $42.2 \%$ versus $36.7 \%$ of Caesarean section being performed for dystocia (12). The dystocia are often diagnosed without monitoring partogram. Thus in every case partogram should be maintained to monitor progress of labour for decreasing rate of Caesarean section.

In our study more Caesarean section were performed in 2005 for foetal distress as compare to 2012 (17.24\% as compared to 13.65\%). These results are consistent with 1962 and 1992 statistics in Glasgow study showing $18.1 \%$ Vs $8.9 \%$ of Caesarean section being performed for foetal distress. A study conducted in tertiary care hospital in India, it was the second leading cause for Caesarean section about 22.2\% (13). Precise interpretation of foetal heart rate tracing and use of foetal $\mathrm{PH}$ might be effective in reducing the Caesarean section rate.

In our study, Caesarean section rate due to hypertensive disorders (PIH/Eclampsia) were found to be increased upto $11.44 \%$ in 2012 as compared to $5.47 \%$ in 2005 . This is consistent with the study conducted by Sajeela et all. and Shamshad et. Al in 2004 and $2008(14,15)$.

In our study Caesarean section rate due to failed induction has increased from $0.54 \%$ in 2005 to $0.83 \%$ in 2012. This is due to availability of better inducing agents. In our study the Caesarean section rate in infertility treated cases and $\mathrm{BOH}$ cases have increased from $3.10 \%$ in 2005 to $4.00 \%$ in 2012 . In BOH Cases and in infertility treated cases pregnancy is precious and obstetrician readily and justifiably resort to early elective Caesarean section. In our study the incidence of Caesarean section due to elderly primi has increased from $0.36 \%$ in 2005 to $0.41 \%$ in 2012 . The elderly primi cases are increasing due to busy life schedule. The incidence of Caesarean section due to medical causes ( e.g. diabetes mellitus ) also increasing in our study from $0.54 \%$ in 2005 to $0.57 \%$ in 2012 to prevent at term mishap of baby. The relation between the increasing rate of Caesarean section and perinatal mortality and morbidity is not consistent, questioning whether Caesarean section benefits the newborn baby (16).

\section{Conclusion}

It would be ideal to initiate obstetric audit by inter departmental meetings to assess the intrinsic role of Caesarean section in influencing the standard management guidelines. The practice of evidence based obstetrics with individualised care according to local set up, would definitely go a long way in balancing the rate of Caesarean section. 


\section{References}

[1] Thomas J, Paranjothy S; Royal College of Obstetrician and gynecologist: Clinical effectiveness support unit. The Nation Sentinel caesarean section Audit report London. RCOG press, 2001.

[2] Hamilton BE, Ventura SJ, Martin JA; Sulton PD. Preliminary births for 2004: Infant and maternal health. Health E - Stats. Released Nov 15, 2005.

[3] Thomas J, Paranjothy S; Royal College of Obstetrician and gynecologist: Clinical effectiveness support unit. The Nation Sentinel caesarean section Audit report London RCOG press, 2001.

[4] Belizan JM, Althabe F; Barros FC; et al. Rates and implications of caesarean section in Latin America: ecological study. BMJ 1999; 319: 1397-402.

[5] Rutkow IM: Obstetric and gynecologic operation in the United States, .1979 to 1984. Obstt. Gynecol 1986;76:755-9

[6] Martin JA: Hamilton BE: Ventura SJ, et al: births: Final data for 2001. Natl Vital Stat Rep 2002; 51:1-102.

[7] Treffers PE, Pel M: The rising trends for caesarean birth. BMJ 1993; 307: 1017-1018

[8] Royal College of Obstetrician and gynaecologist. The national sentinel caesarean section audit report RCOG clinical effectiveness support unit London, RCOG press, 2001.

[9] Murray SF, Serani Pradenas F: Caesarean birth trends in Chile, 1986 to 1994. Birth 1997;24:258-263.

[10] Haider G, Zehra N, Munir AA, Haider A. Frequeny and indication of caesarean section in a tertiary care hospital. Pak J Med Sci 2009:25(5)791-796.

[11] Qazi GR, Akhter S. Obstetrical correlates of the first time c-section, compared with repeated c-section. J Coil Physicians Surg Pak. 2007 0ct;17(10):611- 4.

[12] Leitch CR, Walker JJ. The rise in caesarean section rate: the same indication but a lower threshold. Br J Obstet Gynaecol 1998; 105:621-6.

[13] Pandole A, Rao S, Pawar V, Jain M, Pandit S, Badhwar VR. Changing CV) trends in caesarean section: Would audit make an impact? [Online] 2004. [Cited $\quad$ on 2008 , September $\quad 18]$ Available from URL:www.bhj.org/journal/2004_4505jan/html/changingtrends_25.htm

[14] Noureen S, Khan NH. Changing trends in indication of caesarean section. Medical channel 2010;16:249-52.

[15] Shamshad. Factors leading to increased caesarean section rate. GomalJ Med Sci, 2008:6:1-5

[16] Thiery M, Dermot R. Review on evaluative studies on caesaren section. Part 1: Trends in Caesaren section and perinatal mortality. In Kaminiski M, editor. Perinatal Care Delivery systems. Description and Evaluation in European Community Countries. Oxford: OUP 1986: 93-113.

Tables

Table - 1: Caesarean Section Rate

\begin{tabular}{|c|l|l|l|}
\hline \multicolumn{1}{|c|}{ Year } & $\begin{array}{l}\text { Vaginal Delivery } \\
\text { No(\%) }\end{array}$ & \multicolumn{1}{c|}{$\begin{array}{c}\text { Caesarean section } \\
\text { No }(\boldsymbol{\%})\end{array}$} & Total Delivery \\
\hline 2005 & $13527(86.06)$ & $2192(13.94)$ & 15719 \\
\hline 2012 & $15168(74.31)$ & $5243(25.68)$ & 20411 \\
\hline
\end{tabular}

Table - 2: Indications of Caesarean Section

\begin{tabular}{|l|l|l|}
\hline \multicolumn{2}{|c|}{ Indication } & \multicolumn{2}{c|}{ Year } & \multicolumn{1}{c|}{$\mathbf{2 0 1 2}$} \\
\cline { 2 - 3 } & \multicolumn{1}{c|}{$\mathbf{2 0 0 5}$} & $1832(34.94 \%)$ \\
\hline Previous CS & $618(28.19 \%)$ & $748(14.26 \%)$ \\
\hline Dystocia & $534(24.36 \%)$ & $716(13.65 \%)$ \\
\hline Foetal Distress & $378(17.24 \%)$ & $600(11.44 \%)$ \\
\hline PIH/ Eclampsia & $120(5.47 \%)$ & $148(2.82 \%)$ \\
\hline APH (Placenta Previa, Abruption) & $64(2.91 \%)$ & $204(3.89 \%)$ \\
\hline Breech & $120(5.47 \%)$ & $156(2.97 \%)$ \\
\hline Post Dated & $60(2.73 \%)$ & $276(5.26 \%)$ \\
\hline CPD & $24(1.09 \%)$ & $108(2.05 \%)$ \\
\hline Mal presentation & $42(1.91 \%)$ & $98(1.86 \%)$ \\
\hline Multiple pregnancy & $36(1.64 \%)$ & $210(4.00 \%)$ \\
\hline Infertility treated cases / BOH & $68(3.10 \%)$ & $27(0.51 \%)$ \\
\hline Cord prolapse & $60(2.73 \%)$ & $44(0.83 \%)$ \\
\hline Induction failure & $12(0.54 \%)$ & $24(0.45 \%)$ \\
\hline IUGR & $36(1.64 \%)$ & $30(0.57 \%)$ \\
\hline Medical causes & $12(0.54 \%)$ & $22(0.41 \%)$ \\
\hline Elderly primi & $8(0.36 \%)$ & \\
\hline
\end{tabular}

